Gut and Liver, Vol. 12, No. 2, March 2018, pp. 119-124

\title{
Long-Term Outcomes of Using Endoscopic Submucosal Dissection to Treat Early Gastric Cancer
}

\author{
Toshihiro Nishizawa ${ }^{1,2}$ and Naohisa Yahagi ${ }^{1}$ \\ ${ }^{1}$ Division of Research and Development for Minimally Invasive Treatment, Cancer Center, and ${ }^{2}$ Division of Gastroenterology and Hepatology, \\ Department of Internal Medicine, Keio University School of Medicine, Tokyo, Japan
}

Endoscopic submucosal dissection (ESD) is becoming the main procedure for the resection of early gastric cancer (EGC). The absolute indications for treating EGC with endoscopic resection were established by the Japanese Gastric Cancer Association and have been generally accepted. However, the absolute indications for treating EGC are rather strict, and expanded indications have been developed. Many studies have reported favorable long-term outcomes for patients who received curative resection for the expanded indication. ESD preserves the stomach, thereby improving patients' quality of life compared to surgery; however, a generally higher incidence of metachronous gastric cancer has been reported after ESD for EGC. Therefore, clinicians must pay careful attention during surveillance endoscopy, even after a curative ESD. (Gut Liver 2018;12:119-124)

Key Words: Endoscopic submucosal dissection; Long-term outcomes; Early gastric cancer

\section{INTRODUCTION}

Curative endoscopic resection of early gastric cancer (EGC) has been achieved only in selected patients, depending on the differentiation, size, and depth of invasion of the lesions. The absolute indications for treating EGC with endoscopic resection, established by the Japanese Gastric Cancer Association, have been generally accepted. The absolute indications include differentiated EGCs less than $20 \mathrm{~mm}$ in diameter without ulceration or scarring; moreover, these lesions must be confined to the mucosa, with no lymphatic or vascular involvement (Table 1, Fig. 1).

Endoscopic submucosal dissection (ESD) was developed in Japan in the late 1990s. ESD has been widely used for EGC world- wide. ESD has shown advantages over conventional endoscopic mucosal resection for the removal of larger or ulcerated EGC lesions in an en bloc manner as well as for preventing residual disease and local recurrence. Thus, expanded indications have been developed, including: (1) differentiated mucosal cancers without ulcerative findings, regardless of tumor size; (2) differentiated mucosal cancers with ulcerative findings $<30 \mathrm{~mm}$; and (3) differentiated minute $(<500 \mu \mathrm{m}$ from the muscularis mucosa) submucosal invasive cancers $<30 \mathrm{~mm}$; and (4) undifferentiated mucosal cancers without ulcerative findings $<20 \mathrm{~mm}$, with no lymphatic or vascular involvement (Table 1). ${ }^{1}$ However, some reports showed lymph node metastasis in EGC of expanded indication, especially in submucosal invasive EGC., ${ }^{2,3}$ Recently, the safety and success rates of gastric ESD have improved to favorable levels. Therefore, in this review, we focus up-to-date reports about long-term outcomes of gastric ESD for the better management of patients.

\section{LONG-TERM OUTCOMES OF ESD FOR EGC}

Choi et al. ${ }^{4}$ in Korea assessed the long-term outcome of ESD for the treatment of EGCs (522 lesions). The median follow-up was 24 months. The en bloc resection rate was 97.1\% (333/343) for the absolute indication lesions, 96.1\% (172/179) for expanded indication lesions. The curative resection rate was $91.5 \%$ (314/343) for the absolute indication lesions, 82.1\% (147/179) for expanded indication lesions. The local recurrence rate was 1.8\% for the absolute indication lesions, 7.0\% for expanded indication lesions. No metastatic recurrence occurred during the follow-up period (Table 2).

Kosaka et al. ${ }^{5}$ performed a retrospective analysis of long-term outcomes of ESD for EGC. The range of follow-up period was 5 years to 9 years. The en bloc resection rate was 98.0\% (291/297)

Correspondence to: Naohisa Yahagi

Division of Research and Development for Minimally Invasive Treatment, Cancer Center, Keio University School of Medicine, 35 Shinanomachi, Shinjuku-ku, Tokyo 160-8582, Japan

Tel: +81-3-5363-3437, Fax: +81-3-5363-3895, E-mail: yahagi.keio@gmail.com

Received on February 28, 2017. Revised on March 23, 2017. Accepted on March 23, 2017. Published online July 5, 2017

pISSN 1976-2283 eISSN 2005-1212 https://doi.org/10.5009/gnl17095

@ This is an Open Access article distributed under the terms of the Creative Commons Attribution Non-Commercial License (http://creativecommons.org/licenses/by-nc/4.0) which permits unrestricted non-commercial use, distribution, and reproduction in any medium, provided the original work is properly cited. 
Table 1. Absolute Indications and Expanded Indications for Treating Early Gastric Cancer with Endoscopic Resection

\begin{tabular}{ll}
\hline Absolute indications & Differentiated mucosal cancers $<20 \mathrm{~mm}$, without ulcer findings, no lymphatic vascular invasion \\
Expanded indications & Differentiated mucosal cancers, without ulcer findings, no lymphatic vascular invasion, regardless of tumor size \\
& Differentiated mucosal cancers with ulcer findings $<30 \mathrm{~mm}$, no lymphatic vascular invasion \\
& Differentiated minute $(<500 \mu \mathrm{m})$ submucosal invasive cancers $<30 \mathrm{~mm}$, no lymphatic vascular invasion \\
& Undifferentiated mucosal cancers $<20 \mathrm{~mm}$, without ulcerative findings, no lymphatic vascular invasion
\end{tabular}

Table 2. Long-Term Outcomes of Endoscopic Submucosal Dissection for Early Gastric Cancer

\begin{tabular}{|c|c|c|c|c|c|c|c|c|}
\hline & \multicolumn{2}{|c|}{ Choi et al. $(2013)^{4}$} & \multicolumn{2}{|c|}{ Kosaka et al. $(2014)^{5}$} & \multicolumn{2}{|c|}{ Tanabe et al. $(2014)^{6}$} & \multicolumn{2}{|c|}{ Nakamura et al. (2015) ${ }^{7}$} \\
\hline & AI & EI & AI & EI & AI & EI & AI & EI \\
\hline Follow-up period, median, mo & \multicolumn{2}{|c|}{24} & \multicolumn{2}{|c|}{$>60$} & \multicolumn{2}{|c|}{65} & \multicolumn{2}{|c|}{29.5} \\
\hline No. of patients & 343 & 179 & 297 & 107 & 262 & 159 & 907 & 425 \\
\hline En bloc resection, \% & 97.1 & 96.1 & 98.0 & 89.7 & \multicolumn{2}{|c|}{-} & 99.0 & 97.4 \\
\hline Curative resection, \% & 91.5 & 82.1 & 96.0 & 72.0 & \multicolumn{2}{|c|}{92.9} & 96.4 & 93.4 \\
\hline Local recurrence, no. (\%) & $6(1.8)$ & $13(7.0)$ & $1(0.3)$ & $4(3.7)$ & 0 & $1(0.6)$ & $2(0.2)$ & $4(0.9)$ \\
\hline Metastatic recurrence, no. (\%) & 0 & 0 & 0 & 0 & 0 & $1(0.6)$ & 0 & $1(0.2)$ \\
\hline
\end{tabular}

AI, absolute indication; EI, expanded indication.
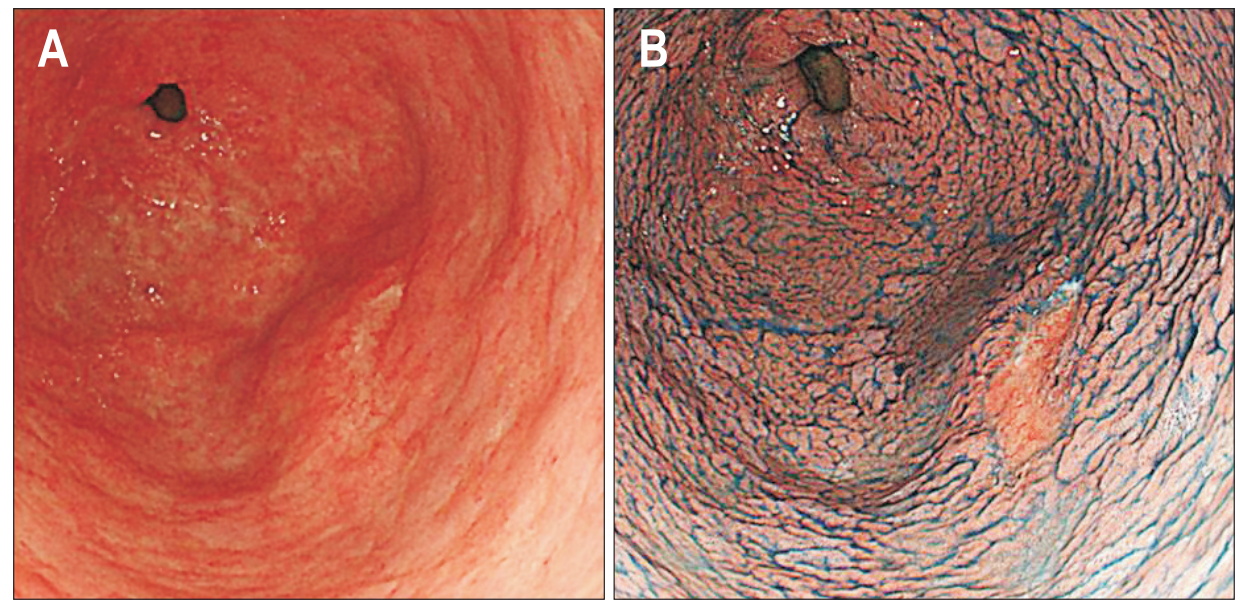

\section{C}

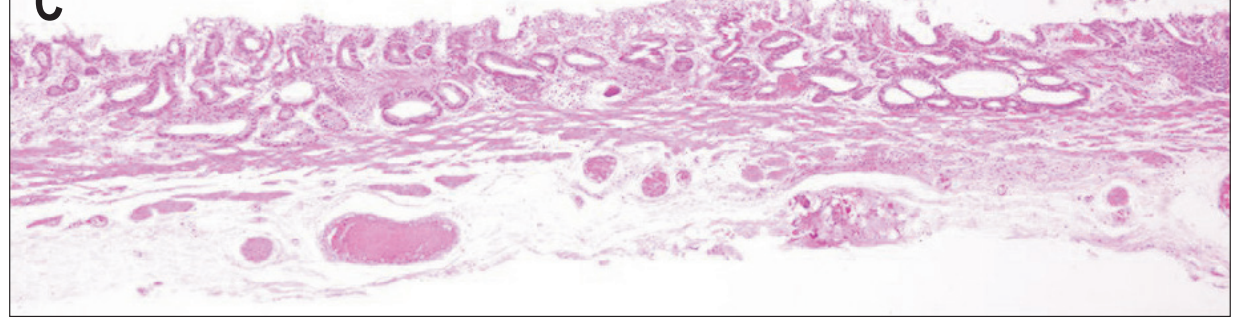

Fig. 1. Absolute indications of early gastric cancer. (A) Early gastric cancer, 0-IIc, $19 \mathrm{~mm}$ at the antrum. (B) Chromoendoscopy with indigo carmine and acetic acid. (C) Differentiated mucosal adenocarcinoma (H\&E stain, $\times 40$ ). for the absolute indication lesions, 89.7\% (96/107) for expanded indication lesions. The curative resection rate was 96.0\% (285/297) for the absolute indication lesions, 72.0\% (77/107) for expanded indication lesions. The local recurrence rate was $0.3 \%$ (1/297) for the absolute indication lesions, 3.7\% (4/107) for the expanded indication lesions. All cases of local recurrence had positive margins or unclear margins. There was no death due to gastric cancer associated with ESD-treated sites (Table 2).
Tanabe et al. ${ }^{6}$ reported long-term outcomes of ESD (421 lesions). The median follow-up was 65 months. The curative resection rate was 92.9\%. The local recurrence rate was $0 \%(0 / 262)$ for the absolute indication lesions, $0.6 \%$ (1/159) for expanded indication lesions. Nodal recurrence occurred in one patient (0.6\%) who had expanded indication lesion (Table 2). The ESD specimen in this case showed poorly differentiated mixed-type mucosal cancer that fulfilled curative resection criteria for ex- 
panded indication.

Nakamura et al. ${ }^{7}$ studied the medical records of EGC $(1,332$ lesions) treated by ESD. The median follow-up was 29.5 months. The en bloc resection rate was $99.0 \%$ for the absolute indication lesions, 97.4\% for expanded indication lesions. The curative resection rate was $96.4 \%$ for the absolute indication lesions, 93.4\% for expanded indication lesions. The local recurrence rate was $0.2 \%$ (2/907) for the absolute indication lesions, 0.9\% (4/425) for the expanded indication lesions. Metastatic recurrence was not seen for the absolute indication lesions but occurred in one case (0.2\%) for expanded indication lesions (Table 2). The ESD specimen in this case showed differentiated type SM1 cancer, $25 \mathrm{~mm}$ in size, without ulceration. Three years after ESD, he was diagnosed with multiple liver metastases and died 1 month later.

\section{LONG-TERM OUTCOMES OF CURATIVE ESD FOR DIFFERENTIATED-TYPE EGC}

Min et al. ${ }^{8}$ reported long-term outcomes after curative ESD for differentiated-type EGC. The median follow-up was 48 months. The local recurrence rates were $0.3 \%(3 / 1,002)$ who had the absolute indication lesions, and $0 \%(0 / 313)$ who had the expanded indication lesions. No metastatic recurrence occurred during the follow-up period. Metachronous gastric cancer occurred in 30 cases (3.0\%) for the absolute indication lesions, and six cases (1.9\%) for the expanded indication lesions (Table 3).

Suzuki et al. ${ }^{9}$ also reported long-term outcomes after curative ESD for differentiated-type EGC. The median follow-up period was 83.3 months. Recurrence was not seen among the patients who had absolute indication lesions. Among the 713 patients with curative ESD for expanded indications, regional lymph node metastasis developed in one patient, and distant lymph node metastasis with local recurrence was noted in one patient. The patient who developed distant lymph node metastasis with local recurrence received systemic chemotherapy but died of gastric cancer 9 years after the ESD. Metachronous gastric cancer occurred in 158 cases (20.2\%) who had absolute indication lesions, and 181 cases (25.4\%) who had expanded indication lesions. Seven cases died of metachronous gastric cancer. The 5-year disease-specific survival rate was 99.9\% who had absolute indication lesions, and 99.9\% who had expanded indication lesions (Table 3).

\section{LONG-TERM OUTCOMES OF ESD FOR UNDIFFERENTIATED-TYPE EGC}

Abe et al. ${ }^{10}$ reported long-term outcomes of ESD carried out to treat undifferentiated EGC. The median follow-up period was 76.4 months. Among the 46 patients with curative resection, none had local recurrence or metastasis. Among the 19 patients with noncurative resection who underwent additional surgery,

Table 3. Long-Term Outcomes of Curative Endoscopic Submucosal Dissection for Differentiated-Type Early Gastric Cancer

\begin{tabular}{|c|c|c|c|c|}
\hline & \multicolumn{2}{|c|}{ Min et al. $(2015)^{8}$} & \multicolumn{2}{|c|}{ Suzuki et al. (2016) ${ }^{9}$} \\
\hline & AI & EI & $\mathrm{AI}$ & EI \\
\hline Follow-up period, median, mo & \multicolumn{2}{|c|}{48} & \multicolumn{2}{|c|}{83.3} \\
\hline No. of patients & 1,002 & 313 & 781 & 713 \\
\hline Local recurrence & $3(0.3)$ & 0 & 0 & $1(0.14)$ \\
\hline Metastatic recurrence & 0 & 0 & 0 & $2(0.3)$ \\
\hline Metachronous gastric cancer & $30(3.0)$ & $6(1.9)$ & $158(20.2)$ & $181(25.4)$ \\
\hline
\end{tabular}

Data are presented as number (\%).

AI, absolute indication; EI, expanded indication.

Table 4. Long-Term Outcomes of Endoscopic Submucosal Dissection as a Treatment for Undifferentiated-Type Early Gastric Cancer

\begin{tabular}{|c|c|c|c|c|c|c|}
\hline & \multicolumn{3}{|c|}{ Abe et al. $(2013)^{10}$} & \multicolumn{3}{|c|}{ Yamamoto et al. $(2014)^{11}$} \\
\hline & $\begin{array}{l}\text { Curative } \\
\text { resection }\end{array}$ & $\begin{array}{l}\text { Noncurative } \\
\text { resection } \\
\text { with surgery }\end{array}$ & $\begin{array}{c}\text { Noncurative } \\
\text { resection } \\
\text { without surgery }\end{array}$ & $\begin{array}{l}\text { Curative } \\
\text { resection }\end{array}$ & $\begin{array}{l}\text { Noncurative } \\
\text { resection } \\
\text { with surgery }\end{array}$ & $\begin{array}{l}\text { Noncurative } \\
\text { resection } \\
\text { without surgery }\end{array}$ \\
\hline Follow-up period, median, mo & \multicolumn{3}{|c|}{76.4} & \multicolumn{3}{|c|}{62.6} \\
\hline No. of patients & 46 & 19 & 14 & 89 & 14 & 6 \\
\hline Local recurrence & 0 & 0 & $1(7.1)$ & 0 & 0 & 0 \\
\hline Metastatic recurrence & 0 & $1(5.3)$ & 0 & 0 & 0 & 0 \\
\hline Metachronous or synchronous cancer & $6(13)$ & - & - & $7(7.9)$ & $1(7.1)$ & 0 \\
\hline
\end{tabular}

Data are presented as number (\%). 
there was one case of distant metastasis (5.3\%). The ESD specimen in this case showed SM2 cancer, $44 \mathrm{~mm}$ in size, with lymphatic invasion. Among the 14 patients with noncurative resection who did not undergo additional surgery, there was one case of local recurrence (7.1\%). Metachronous gastric cancer occurred in six cases (13\%) with curative resection (Table 4).

Yamamoto et al. ${ }^{11}$ also reported long-term outcomes of ESD carried out to treat undifferentiated EGC (109 patients). The median follow-up period was 62.6 months. None had local recurrence or metastasis. Among the 89 patients with curative resection, synchronous gastric cancer was found in five cases, and metachronous gastric cancer occurred in two cases. The 5-year disease-specific survival rate was $97.5 \%$ for the curative ESD cases. Among the 14 patients with noncurative resection who underwent additional surgery, synchronous gastric cancer was found in one case (Table 4). These findings indicate that the expanded indication for undifferentiated EGC is reasonable. It is important that patients with noncurative resection undergo additional surgery, since malignant potential is much higher in undifferentiated EGC.

\section{LONG-TERM OUTCOMES OF GASTRIC ESD BEYOND EXPANDED INDICATION}

Endo et al. ${ }^{12}$ reported long-term outcomes of ESD beyond the expanded indication. The en bloc resection rate and complete resection rate were both 100\% (57/57). Among the 44 patients who underwent additional surgery, none had local recurrence or metastasis. Five patients died from other causes. The 5-year disease-specific survival rate was 100\%, and 5-year overall survival rate was $86.4 \%$. Among the 13 patients who did not undergo additional surgery, none had local recurrence or metastasis. Three patients died from other causes. The 5-year diseasespecific survival rate was 100\%, and 5-year overall survival rate was 76.9\% (Table 5).

Kang et al. ${ }^{13}$ also reported long-term outcomes of ESD beyond the expanded indication. The rate of en bloc resection, complete resection, free lateral margin and free vertical margin were $86.3 \%, 41.2 \%, 66.7 \%$, and 52.9\%. The 39 patients did not wish to undergo additional surgery, because of concerns over the intractability of their disease. The local recurrence rate was $10.3 \%$ (4/39). Lymph node metastasis occurred in two patients (5.1\%). The 5-year disease-specific survival rate and 5-year overall survival rate were both $97.4 \%$ for ESD beyond the expanded indication (Table 5).

\section{ESD VERSUS SURGICAL RESECTION FOR EGC}

Ryu et al. ${ }^{14}$ compared ESD and surgical resection that met the expanded indication of differentiated-type EGC with a followup period of more than 5-years. The complete resection rates were 92.6\% (75/81) for ESD treatment, and 100\% (144/144) for surgery. The local recurrence rates were 4.9\% (4/81) after ESD and 1.4\% (2/144) after surgical resection. No metastatic recurrence occurred during the follow-up period. Metachronous gastric cancer occurred in 6.2\% (five cases) after ESD and 0.7\% (one case) after surgical resection. Hospital stay was 7 days for ESD, and 13 days for surgical resection. Hospital stay of ESD was shorter than that of surgical resection $(p<0.001)$. The overall early complication rates were $12.3 \%$ in ESD and $23.6 \%$ in surgical resection $(\mathrm{p}=0.041)$. The late complications, including bleeding, ileus, ascites, and dumping syndrome, was higher in surgery group (9.7\%) than ESD group (3.7\%) (Table 6).

Cho et al. ${ }^{15}$ compared ESD and surgical resection that met the expanded indication of EGC using propensity score-matched analysis. The local recurrence rates were 3.4\% (3/88) after ESD and $0 \%(0 / 88)$ after surgical resection. No metastatic recurrence occurred during the follow-up period. Metachronous gastric cancer occurred in 3.4\% (three cases) after ESD and 0\% after surgical resection. Hospital stay was $7.3 \pm 2.9$ days for ESD and $14.2 \pm 8.4$ days for surgical resection. Hospital stay of ESD was shorter than that of surgical resection $(\mathrm{p}<0.001)$. The overall early complication rates were $8.0 \%$ in ESD and 5.7\% in surgical resection. The late complication rates were $0 \%$ in ESD and 6.8\% in surgical resection (Table 6). The late complications after surgery included stricture, ileus, and marginal ulcer.

Fukunaga et al. ${ }^{16}$ evaluated the long-term outcomes for patients with expanded-indication lesions of differentiated-type EGC who underwent ESD or surgical treatments. After propensity score matching, the 5-year overall survival rate was higher

Table 5. Long-Term Outcomes of Gastric Endoscopic Submucosal Dissection beyond the Expanded Indication

\begin{tabular}{|c|c|c|c|}
\hline & \multicolumn{3}{|c|}{ Additional treatment } \\
\hline & \multicolumn{2}{|c|}{ Endo et al. $(2014)^{12}$} & \multirow{2}{*}{$\frac{\text { Kang et al. }(2015)^{13}}{\text { None }}$} \\
\hline & Surgery & None & \\
\hline No. of patients & 44 & 13 & 39 \\
\hline Local recurrence, no. (\%) & 0 & 0 & $4(10.3)$ \\
\hline Metastatic recurrence, no. (\%) & 0 & 0 & $2(5.1)$ \\
\hline 5-Year disease-specific survival, \% & 100 & 100 & 97.4 \\
\hline 5-Year overall survival, \% & 86.4 & 76.9 & 97.4 \\
\hline
\end{tabular}


Table 6. ESD versus Surgical Resection for Early Gastric Cancer

\begin{tabular}{|c|c|c|c|c|}
\hline & \multicolumn{2}{|c|}{ Ryu et al. (2016) ${ }^{14}$} & \multicolumn{2}{|c|}{ Cho et al. (2016) } \\
\hline & ESD & Surgery & ESD & Surgery \\
\hline No. of patients & 81 & 144 & 88 & 88 \\
\hline Complete resection, \% & 92.6 & 100 & 90.1 & 100 \\
\hline Local recurrence, \% & 4.9 & 1.4 & 3.4 & 0 \\
\hline Metastatic recurrence, $\%$ & 0 & 0 & 0 & 0 \\
\hline Metachronous gastric cancer, $\%$ & 6.2 & 0.7 & 3.4 & 0 \\
\hline Hospital stay, median (range) or mean \pm SD, day & $7(2-25)$ & $13(6-49)$ & $7.3 \pm 2.9$ & $14.2 \pm 8.4$ \\
\hline Early complication, \% & 12.3 & 23.6 & 8.0 & 5.7 \\
\hline Rate complication, \% & 3.7 & 9.7 & 0 & 6.8 \\
\hline
\end{tabular}

ESD, endoscopic submucosal dissection.

in the ESD group than in the surgery group (97.1\% vs $85.8 \%$, $\mathrm{p}=0.01$ ). Significantly fewer adverse events were associated with ESD than with surgery (6.8\% vs $28.4 \%$, p<0.01). No causespecific mortality was observed in either group.

\section{DISCUSSION}

The available literature suggests that the long-term outcomes of ESD are acceptable for EGC. Compared with surgery, the benefits of ESD included fewer complications and shorter hospital stay duration. ESD preserves the stomach thereby improving patients' quality of life compared to surgery, but a generally higher incidence of metachronous gastric cancer has been reported after ESD for EGC. Metachronous gastric cancer or local recurrence could be treated by ESD, if the lesion is detected early enough. Therefore, more careful attention must be paid during surveillance endoscopy after ESD.

A systematic review and meta-analysis assessed the application of expanded indications by comparing outcomes between absolute indication and expanded indication groups. ${ }^{17}$ Thirteen studies were identified and evaluated. The expanded indication group had lower rates of en bloc resection (93.6\% vs 97.0\%, $\mathrm{p}<0.0001)$ and complete resection (87.8\% vs 95.8\%, $\mathrm{p}<0.00001)$ than the absolute indication group. Local recurrence rates were lower in the absolute indication group than in the expanded indication group ( $0.6 \%$ vs $1.5 \%, p=0.03)$. There were no significant differences between the two groups in the gastric-cancer specific mortality and the overall mortality. These findings indicate that the expanded indication is reasonable if patients are properly selected.

On the other hand, patients with intractable disease cannot undergo surgery due to high operation risk. Palliative ESD for lesions beyond the expanded indication might be treatment option for patients with intractable disease in the future.

The key to improve therapeutic outcomes for EGC is early detection and accurate diagnosis. ${ }^{18,19}$ Early detection of gastric cancer or precancerous lesion is essential to curative ESD.
Recently, several advances in diagnostic endoscopy including narrow-band imaging, and magnifying endoscopy have allowed improvement in tissue characterization by detailed imaging of the microvascular pattern and mucosal surface structures. Moreover, identifying a precise demarcation line is indispensable for pathological complete en bloc resection. Chromoendoscopy with indigo carmine and acetic acid is useful for creating precise markings before gastric ESD (Fig. 1). ${ }^{20}$

Over the past decades, the refinements in ESD techniques, instruments, and devices have been achieved. The safety and success rates of gastric ESD have recently improved to favorable levels. Further development of training systems will promote world-wide standardization of gastric ESD.

\section{CONCLUSIONS}

These findings indicate that ESD represents a highly effective treatment modality for EGC. However, the results of all studies were obtained from a retrospective assessment based on the medical records. Thus, a prospective multicenter study with high follow-up rate is required for more precise evaluation of the long-term outcomes of gastric ESD.

\section{CONFLICTS OF INTEREST}

No potential conflict of interest relevant to this article was reported.

\section{REFERENCES}

1. Gotoda T, Yanagisawa A, Sasako M, et al. Incidence of lymph node metastasis from early gastric cancer: estimation with a large number of cases at two large centers. Gastric Cancer 2000;3:219225.

2. Ahn JY, Jung HY, Choi KD, et al. Endoscopic and oncologic outcomes after endoscopic resection for early gastric cancer: 1370 cases of absolute and extended indications. Gastrointest Endosc 
2011;74:485-493.

3. Kang HJ, Kim DH, Jeon TY, et al. Lymph node metastasis from intestinal-type early gastric cancer: experience in a single institution and reassessment of the extended criteria for endoscopic submucosal dissection. Gastrointest Endosc 2010;72:508-515.

4. Choi MK, Kim GH, Park DY, et al. Long-term outcomes of endoscopic submucosal dissection for early gastric cancer: a singlecenter experience. Surg Endosc 2013;27:4250-4258.

5. Kosaka T, Endo M, Toya Y, et al. Long-term outcomes of endoscopic submucosal dissection for early gastric cancer: a singlecenter retrospective study. Dig Endosc 2014;26:183-191.

6. Tanabe S, Ishido K, Higuchi K, et al. Long-term outcomes of endoscopic submucosal dissection for early gastric cancer: a retrospective comparison with conventional endoscopic resection in a single center. Gastric Cancer 2014;17:130-136.

7. Nakamura K, Honda K, Akahoshi K, et al. Suitability of the expanded indication criteria for the treatment of early gastric cancer by endoscopic submucosal dissection: Japanese multicenter largescale retrospective analysis of short- and long-term outcomes. Scand J Gastroenterol 2015;50:413-422.

8. Min BH, Kim KM, Park CK, et al. Outcomes of endoscopic submucosal dissection for differentiated-type early gastric cancer with histological heterogeneity. Gastric Cancer 2015;18:618-626.

9. Suzuki H, Oda I, Abe S, et al. High rate of 5-year survival among patients with early gastric cancer undergoing curative endoscopic submucosal dissection. Gastric Cancer 2016;19:198-205.

10. Abe S, Oda I, Suzuki H, et al. Short- and long-term outcomes of endoscopic submucosal dissection for undifferentiated early gastric cancer. Endoscopy 2013;45:703-707.

11. Yamamoto Y, Fujisaki J, Miyamoto Y, et al. The long term prognosis of expanded indication lesion of endoscopic submucosal dissection for undifferentiated type early gastric cancer. Stomach
Intest 2014:49:1569-1577.

12. Endo M, Kosaka T, Toya Y, et al. Long-term outcomes and prognosis of noncurative cases after endoscopic submucosal dissection for gastric cancer. Stomach Intest 2014;49:1583-1591.

13. Kang MS, Hong SJ, Kim DY, et al. Long-term outcome after endoscopic submucosal dissection for early gastric cancer: focusing on a group beyond the expanded indication. J Dig Dis 2015;16:7-13.

14. Ryu SJ, Kim BW, Kim BG, et al. Endoscopic submucosal dissection versus surgical resection for early gastric cancer: a retrospective multicenter study on immediate and long-term outcome over 5 years. Surg Endosc 2016;30:5283-5289.

15. Cho JH, Cha SW, Kim HG, et al. Long-term outcomes of endoscopic submucosal dissection for early gastric cancer: a comparison study to surgery using propensity score-matched analysis. Surg Endosc 2016;30:3762-3773.

16. Fukunaga S, Nagami Y, Shiba M, et al. Long-term prognosis of expanded-indication differentiated-type early gastric cancer treated with endoscopic submucosal dissection or surgery using propensity score analysis. Gastrointest Endosc 2017;85:143-152.

17. Peng LJ, Tian SN, Lu L, Chen H, Ouyang YY, Wu YJ. Outcome of endoscopic submucosal dissection for early gastric cancer of conventional and expanded indications: systematic review and metaanalysis. J Dig Dis 2015;16:67-74.

18. Ko WJ, Song GW, Kim WH, Hong SP, Cho JY. Endoscopic resection of early gastric cancer: current status and new approaches. Transl Gastroenterol Hepatol 2016;1:24.

19. Nishizawa T, Suzuki H, Arano T, et al. Characteristics of gastric cancer detected within 1 year after successful eradication of Helicobacter pylori. J Clin Biochem Nutr 2016;59:226-230.

20. Iizuka T, Kikuchi D, Hoteya S, Yahagi N. The acetic acid + indigocarmine method in the delineation of gastric cancer. J Gastroenterol Hepatol 2008;23:1358-1361. 